\title{
Moral Reasoning and Emotion
}

\author{
Joshua May \& Victor Kumar \\ Published in The Routledge Handbook of Moral Epistemology, \\ eds. Karen Jones, Mark Timmons, and Aaron Zimmerman, Routledge (2018), pp. 139-156.
}

\begin{abstract}
This chapter discusses contemporary scientific research on the role of reason and emotion in moral judgment. The literature suggests that moral judgment is influenced by both reasoning and emotion separately, but there is also emerging evidence of the interaction between the two. While there are clear implications for the rationalism-sentimentalism debate, we conclude that important questions remain open about how central emotion is to moral judgment. We also suggest ways in which moral philosophy is not only guided by empirical research but continues to guide it.
\end{abstract}

Word count: 9,310 (all inclusive)

\section{Introduction}

Unless presently in a coma, you cannot avoid witnessing injustice. You will find yourself judging that a citizen or a police officer has acted wrongly by killing someone, that a politician is corrupt, that a social institution is discriminatory. In all these cases, you are making a moral judgment. But what is it that drives your judgment? Have you reasoned your way to the conclusion that something is morally wrong? Or have you reached a verdict because you feel indignation or outrage?

Rationalists in moral philosophy hold that moral judgment can be based on reasoning alone. Kant argued that one can arrive at a moral belief by reasoning from principles articulating one's duties. Sentimentalists hold instead that emotion is essential to distinctively moral judgment. Hume, Smith, and their British contemporaries argued that one cannot arrive at a moral belief without experiencing appropriate feelings at some point-e.g. by feeling compassion toward victims or anger toward perpetrators. While many theorists agree that both reason and emotion play a role in ordinary moral cognition, the dispute is ultimately about which process is most central.

Controversies about the comparative roles played by reasoning and emotion in moral judgment have important implications for the nature of moral knowledge. Some sentimentalists suggest that there are no moral facts to be known, for ethics is ultimately a matter of merely having or expressing one's feelings. Even if rationalism isn't the only way to support a more objectivist conception of morality, it may allow more room for knowing right from wrong. After all, if moral judgment is fundamentally a rational enterprise, then we can ultimately form moral beliefs that are based on good reasons. However, sentimentalists might argue that they also make moral knowledge possible, perhaps even easier to attain: you just need to have the right emotional responses. Ethical knowledge may just resemble perception more than mathematical 
reasoning. Such theoretical disputes also impact several practical questions about how to resolve moral disagreements, possess ethical wisdom, or even build a robot capable of making genuine moral judgments. Do the morally inept just need to be more compassionate or angry? Or do we become ethically wise by reasoning better, by freeing ourselves of cognitive biases that make us overconfident, inconsistent, wishful thinkers who neglect base rates?

The debate between rationalists and sentimentalists is partly an empirical one. Philosophers in centuries past addressed the debate by drawing on the understanding of the mind available at that time. However, there is now a large and growing body of rigorous empirical research in cognitive science that promises to shed new light on the psychological and neurological mechanisms underlying moral judgment.

To interpret empirical research on moral judgment, we need to adopt at least a provisional distinction between reasoning and emotion. It's tempting to assume that reasoning is always conscious or that reasoning is the only psychological process that involves information processing. Neither of these assumptions is useful. Quite a bit of reasoning is unconscious and many if not all emotions involve information processing. The assumption that reasoning is always conscious stacks the deck in favor of sentimentalism, while the assumption that only reasoning involves information processing stacks it in favor of rationalism. We will attempt to contrast reason and emotion in a more neutral way: emotional processing involves states that are inherently affective or valenced; reasoning is an inferential process that forms new beliefs on the basis of existing ones. While reason and emotion may be distinct, they can be intimately bound together, as when feelings facilitate inference. Accordingly, as we'll see, it's difficult to empirically pry apart reason and emotion to determine which is more fundamental or essential to moral cognition.

In this chapter, we review the state of play in contemporary research on moral judgment in cognitive science, formulate hypotheses about where this research is heading, and unpack its philosophical significance. We canvass evidence that moral judgment is influenced by both reasoning and emotion separately, but we also examine emerging evidence of the interaction between the two. Throughout the chapter, we discuss the implications of this body of evidence on the rationalism-sentimentalism debate and ultimately conclude that important questions remain open about how central emotion is to moral judgment. We also suggest ways in which moral philosophy is not only guided by empirical research but continues to guide it.

\section{Reasoning}

The paradigm of reasoning is conscious and deliberate (Haidt 2001; Paxton et al. 2011). You calculate your portion of the dinner bill by applying the principles of arithmetic; you lie awake at night deliberating about how to pitch the proposal in the board meeting; you stare at the gizmo and run through all the possibilities of what might be causing it to malfunction. In such cases, you're consciously aware of your reasoning and of at least some of the steps and principles applied.

Reasoning can most certainly be unconscious as well. Suppose ten days ago you resolved to avoid Mr. Williams, and upon seeing him today in the lobby you immediately jump behind a wall to avoid being detected. Or suppose you're watching a film, apparently passively, and the first fifteen minutes include no dialogue but merely ambiguous social interactions and facial expressions; you find yourself suspecting there is a checkered romantic history between the two 
characters. These examples require inference, but the reasoning is automatic and largely unconscious.

Like other forms of cognition, moral judgment seems to involve both implicit and explicit reasoning. This is likely a consequence of our dual process minds. We have two general systems for information processing: one is faster, more automatic, and perhaps based on fairly rigid heuristics; the other is slower, more controlled, and less constrained by heuristics (Kahneman 2011; cf. Railton 2014; Kumar 2017b). Automatic processing is more efficient, since it's fast and uses fewer resources, but controlled processing is more flexible (Greene 2014). Our minds presumably evolved this dual process architecture in order to allow for both advantages. However, a dual-processing architecture may not be required to capture the distinction between conscious and unconscious moral reasoning (Kennett \& Fine 2009; Mikhail 2011).

\subsection{Conscious Reasoning}

We now have ample evidence that moral cognition likewise exhibits a duality in the types of cognitive processes that generate it. The most prominent tool for empirically probing moral judgment involves sacrificial dilemmas in which one is effectively asked whether the needs of the many outweigh those of the few. In the famous trolley scenarios, often one is supposed to imagine that an individual has the opportunity to save five innocent people from impending death but at the cost of the death of one innocent person. The protagonist can either let the five die or sacrifice the one. Participants are asked to report which choice they believe is morally appropriate.

A growing amount of evidence suggests that as various factors change so do our modes of moral thinking. Consider the contrast between two famous trolley cases. In Switch, an individual in the vignette can throw a switch to divert a train from killing five innocent people but then it will kill one innocent person on a side-track. The vast majority of people from various countries and cultures believe it's morally acceptable to sacrifice the one and save the five (Hauser et al. 2007; Mikhail 2011). However, most people do not believe it's morally permissible to sacrifice the one if he must be pushed in the way of the train in order to stop it, as in the Footbridge case. Neuroimaging indicates that distinct areas of the brain are more active when evaluating such personal versus impersonal dilemmas (Greene 2014). In impersonal dilemmas like Switch, where we simply weigh up the outcomes (one death is better than five), there's greater activation of brain areas generally involved with calculative reasoning and working memory, especially the dorsolateral prefrontal cortex (DLPFC). This appears to be moral thinking that's more controlled than automatic. When evaluating personal dilemmas, such as Footbridge, we consider that the protagonist must get more physically involved in bringing about one death to prevent five. This involves greater activity in brain areas generally associated with more automatic and emotional processing, particularly the ventral medial prefrontal cortex (VMPFC).

Now, it's quite controversial what kinds of moral intuitions are being measured here. Greene argues that the controlled processes generally lead to characteristically utilitarian moral intuitions concerned with promoting the greater good, while the automatic processes lead to nonutilitarian (e.g. deontological) intuitions concerned with avoiding up-close and personal harm. Other researchers argue that the dilemmas really contrast reasoning about intuitive versus counterintuitive moral dilemmas (Kahane et al. 2012) and that the "utilitarian" choice does not reflect impartial concern for maximizing welfare (Kahane et al. 2015). What's clear, though, is 
that there is some neurophysiological evidence for the independently plausible claim that the cognitive processes in moral cognition can be either automatic or controlled.

Other research might seem to suggest that conscious moral reasoning is causally impotent. Moral judgments may be driven primarily by automatic intuitions while deliberate reasoning is merely post hoc rationalization, used to justify what one already believes on intuitive grounds (Haidt 2001). Consider, for example, evaluating a so-called "harmless taboo violation," such as eating an already dead dog, cleaning a toilet with your national flag, or passionately kissing your sibling. When participants are presented with brief descriptions of such scenarios, they often think they are immoral but struggle to explain why - they're in a state of moral dumbfounding (Haidt et al. 1993). As Haidt puts it, one is like a "lawyer trying to build a case rather than a judge searching for the truth" (2001: 814).

There are several reasons why moral dumbfounding does not undermine the existence of moral reasoning. First, one's inability to articulate a justification for one's moral belief doesn't rule out that one arrived at it by unconscious reasoning or computation (Dwyer 2009). Further research does suggest that taboo violations are seen as causing harm, including long-term psychological damage (Royzman et al. 2009; Royzman et al. 2015). Of course you will be dumbfounded when an experimenter challenges your quite reasonable assumption that there is any harm to eating a deceased pet. Ordinarily, this act would bring pet lovers a great deal of psychological harm or distress.

There are also a number of different ways in which consciously controlled reasoning can influence moral judgment. Automatic and implicit racial biases, for example, can be deliberately suppressed or even eliminated (see discussion in Kennett \& Fine 2009). When making snap judgments, many of us are more prone to misidentify a tool as a gun when held by a black man rather than a white man. However, there is some evidence that one can become less susceptible to such biases by consciously thinking "Whenever I see a Black face on the screen, I will think the word, safe" (Stewart and Payne 2008: 1336). While the relevant studies on implicit bias don't clearly measure moral judgments, other experiments do. For example, more reflective people provide more "utilitarian" responses to sacrificial moral dilemmas, and judgments are further modulated by the strength of an argument and the length of time allowed for deliberation (e.g. Paxton et al. 2011; for discussion of further studies, see Greene 2014: 704).

\subsection{Unconscious Reasoning}

Moral psychology used to emphasize the kind of conscious reasoning that we articulate when justifying a moral judgment (Kohlberg 1973). The focus of research in this area has rightly widened in response to evidence that a surprising amount of moral thinking is automatic, implicit, and unconscious. Instead of asking participants to justify moral beliefs about a particular case, researchers now focus on patterns of intuitive responses to hypothetical moral dilemmas in order to reveal the structure of moral cognition. However, contrary to some accounts (e.g. Haidt 2001), these unconscious processes can be quite sophisticated. And this may provide good grounds on which to count it as a form of reasoning (Horgan \& Timmons 2007; Mallon \& Nichols 2010; Mikhail 2011).

One important element to survive the shift in focus is the historically (and legally) foundational contrast between an intentional action and an accident. For example, we are more inclined to condemn poisoning a coworker by mixing a deadly white substance into his coffee when it's done purposefully rather than accidentally. Moreover, the consequences are not 
entirely paramount here, even when evaluating the morality of the individual's action and not her motives or character. For example, many people think the protagonist's action is wrong so long as she intended harm, even if she didn't in fact inflict any, because what she took to be arsenic was only sugar (Young et al. 2007). It seems "no harm, no foul" only applies when harm fails to result from an accidental risk of damage. Studies using brain imaging and stimulation suggest that these relatively automatic judgments employ brain areas associated with perceiving others' mental states, particularly the right temporal parietal junction (Young et al. 2007; Young et al. 2010). Indeed, some researchers claim that this capacity for "mind perception" is essential to all moral judgment (Gray, Young, \& Waytz 2012).

There are certainly other computational elements of moral cognition as well. In one experiment, participants judged a battery of moral dilemmas that varied along three dimensions: whether an outcome arose from an action or omission, an intention or side-effect, and through bodily contact or at a distance (Cushman et al. 2006). Each factor tended to affect people's moral judgments, but participants weren't always able to consciously identify them. Further studies and meta-analyses confirm that a variety of moral responses are reliably influenced, even if only slightly, by these factors across various cultures (see e.g. Hauser et al. 2007; May 2014b; Feltz \& May 2017).

Even if we can sometimes later identify the relevant factors affecting our earlier moral judgments, plausibly their initial influence on moral judgment is largely unconscious. Of course, if a moral dilemma is particularly complex or one's consideration of it drawn out, one may be consciously aware of some inferential steps leading to the moral judgment. But ordinary experience and rigorous empirical evidence suggest that some moral beliefs are generated by rapid inference even about relatively simply scenarios. Some theorists suggest moral cognition in many ways resembles knowledge of a language in being underwritten by largely automatic, yet complex, computations in the brain (Dwyer 2009; Mikhail 2011). Studies in cognitive neuroscience are beginning to identify the brain regions involved in moral competence, which include neural structures independently correlated with our efforts to rapidly discern the intentions of others and the casual effects of actions (Young et al. 2007; Crockett 2013; Yoder \& Decety 2014).

Evidence for relatively unconscious moral reasoning isn't limited to unrealistic trolley scenarios. Some of the studies already cited measure participants' reactions to more ordinary situations, such as drowning and overdosing (e.g. Cushman et al. 2006). Studies of rationalization and motivated reasoning also reveal rapid and unconscious moral reasoning. For example, in a series of clever experiments (e.g. Batson et al. 1999), participants had to assign a rewarding task or benefit to either themselves or a stranger. If given the choice in public, many participants opted for a fair procedure, such as flipping a coin, for determining who was to receive the benefit. However, when allowed to employ this procedure in private, participants overwhelmingly assigned themselves the benefit, at rates much greater than chance (around $90 \%$ ). Clearly there was some fiddling of the flip or fudging of the results. This is evidence of a motivation to merely appear moral without bearing the costs of actually being moral - a kind of egoistic "moral hypocrisy" that many people fail to recognize in themselves.

More interesting for our purposes is that those who flipped the coin, yet disregarded its dictates, appeared to rationalize their behavior. They rated their assignment as significantly more moral than those who simply chose not to flip and just assigned themselves the benefit. Albeit self-deceived and relatively unconscious, this is reasoning ("motivated reasoning") that leads to a change in moral belief (see May 2018). Such studies reveal that even if rationalism is true, 
moral judgment isn't necessarily "rational" (cf. Greene 2008). Moral reasoning is susceptible to biases that can debunk the judgments it produces, at least once we recognize the influence of these biases (see Kumar and May forthcoming).

Of course, sentimentalists might attempt to ground unconscious moral cognition in emotional processing. Perhaps, for example, reasoning about a person's motives depends ultimately on the more emotional aspects of sympathy or empathy. There is at best a fine line between affectively valenced information processing and unconscious reasoning about motives and consequences. Extant evidence may not be sufficiently fine-grained to favor one of these accounts.

\section{Emotion}

According to Hume, Smith and their philosophical heirs, empathy is an essential foundation of moral judgment. Reasoning may be required to discern the consequences of an act, but one can't make a distinctively moral judgment if one is incapable of feeling some semblance of the pain or pleasure caused by the act. In this context, "empathy" denotes the emotional capacity to imaginatively project oneself into another person's situation and feel what they feel. It is because you feel bad when you imagine the pain of a victim that you are led to condemn the person who harmed her. According to some sentimentalists, however, other emotional capacities aside from empathy are implicated in moral thought (Nichols 2004; Prinz 2007; Kauppinen 2013). We feel anger toward those who violate a moral norm, even if we do not empathize with the victim, even when the crime is victimless. We feel contempt toward those who presume an air of authority that is illegitimate. We feel disgust toward people who commit crimes against "nature," but also toward dishonest lawyers and hypocritical politicians.

Moral judgment is, of course, partly evaluative rather than entirely descriptive. And many philosophers and psychologists have long held that human values are in some sense "grounded in" emotion. Anti-realists in ethics hold that emotions are used to paint the world with value, much as one's visual experiences are used to paint the world with color. Psychologists since the 1980s have thought that emotion is "the currency of value" in the brain or the vehicle it employs to represent what's good or bad. So there is good reason to explore whether there is any empirical evidence for the idea that emotions play a distinctive role in moral judgment. We will begin by examining relatively indirect evidence and then turn to more direct evidence for this sentimentalist idea.

\subsection{Indirect Evidence}

The idea that emotions are implicated in moral judgment is reinforced by evolutionary and developmental considerations. Arguably, the evolutionary roots of morality lie in emotion (Kumar and Campbell ms). For example, we feel sympathy or concern for many of our fellow humans and this is what underlies values that enjoin care and discourage harm. Individuals who lack properly functioning emotions are said to exhibit disorders in moral agency. Psychopathy is a developmental disorder that is characterized in part by diminished sympathy and guilt and dysfunction in the VMPFC and amygdala. Besides being cruel and callous, psychopaths appear to show deficits in moral judgment. In some studies, psychopaths are unable to reliably 
distinguish between violations of moral norms and violations of mere convention (Blair 1995, 1997, Blair et al. 1995; cf. Aharoni et al. 2012).

However, the roots of psychopathy lie in childhood, which means that emotional deficits may disrupt only the development, not deployment, of moral judgment (see Kumar 2016a). So, even if we accept a developmental link between emotion and valuation, rationalists might still deny that emotions play a role in mature moral judgment. What non-psychopaths retain may simply be a capacity for moral reasoning that is shaped in development by emotion. In support of this idea, patients who suffer from damage to the VMPFC in adulthood engage in anti-social behavior that is in some ways similar to psychopaths' behavior, but they do not exhibit the same apparent deficits in moral judgment (Saver and Damasio 1991; Taber-Thomas et al. 2014; Roskies 2003). Emotions, then, may not be as essential to the proximate causes of moral judgment as experiences of color are to color judgments (May 2018). To get clear on whether emotion plays a more integral role, we must turn to experimental evidence that targets occurrent moral cognition.

As noted earlier, some research suggests that conscious reasoning exerts little influence on moral judgment. People can readily offer reasons for their judgments, but in some cases the judgment is automatic and the reasons are only articulated after the fact. It's worth repeating that this does not show that reasoning is inert, since automatic moral judgments may be based on unconscious reasoning, perhaps from the very factors one uses to defend the judgments when pressed after the fact. However, in some cases, it may be that emotions generate automatic moral judgments that aren't (also) grounded in reasoning. In Haidt's studies of moral dumbfounding, some participants condemn actions that are apparently harmless but disgusting or emotionally evocative in other ways. Yet they maintain these judgments even when their verbal grounds for condemnation are impugned by the facts of the case as it's described. It is generally thought that affective states are a common source of automatic heuristics that generate an immediate and intuitive judgment in a number of domains, not only in ethics (Damasio 1994; Greene 2014; Railton 2014). Thus it may be emotion more than unconscious reasoning that leads participants to judge that it is wrong to have sex with one's sibling, to eat the family pet after it has been killed, to clean the toilet with the country flag.

Some moral violations seem emotionally evocative, but are there any more decisive reasons to believe that emotions are at play in moral evaluation? Neurophysiological evidence promises to shed light on this issue, since neuroscientists have identified several areas of the brain that have been independently correlated with the expression and experience of emotion. When participants are presented with sacrificial moral dilemmas that are personal rather than impersonal, neuroimaging shows activity in VMPFC, along with more ancient areas of the brain underlying emotion, like the amygdala and the insular cortex.

Still, this neuroscientific evidence doesn't guarantee that emotions are a cause of moral judgments. Even if we can reasonably draw "reverse inferences" from brain activation to mental process, it may be that emotions are not "upstream" of moral judgment. There are two other live possibilities. First, it may be that conscious or unconscious reasoning generates moral judgments, and that these judgments then produce emotional responses "downstream." Second, it may be that some morally salient events elicit emotions, but this emotional process runs in parallel and does not influence moral judgment (the two are elements of distinct "tributaries"). More direct experimental evidence is needed to distinguish these hypotheses. This evidence promises to reveal whether or not the automatic, unconscious information processing that underlies moral judgment is affectively valenced. 


\subsection{Direct Evidence}

Manipulation studies provide an attractive methodology for studying whether emotions are upstream of moral judgment, not just implicated in or correlated with moral development. In these studies, psychologists directly or indirectly induce emotion in participants and explore whether this changes their moral judgments relative to control groups whose emotional states have not been manipulated.

So far, manipulation studies have made most use of disgust, in part because it is often easier and ethically more acceptable to induce disgust in participants (rather than, say, anger). A range of studies seems to suggest that participants tend to make more severe negative moral judgments when they are asked to sit at a messy desk, exposed to a foul odor, or presented with a disgusting short film (Schnall et al. 2008), when they are primed to feel disgust by given the opportunity to use hand soap (Helzer \& Pizarro 2011), and when they are hypnotized to feel disgust at the mention of certain neutral words (Wheatley and Haidt 2005). A few manipulation studies have also induced anger by asking participants to listen to unpleasant music (Seidel and Prinz 2013a, 2013b). These studies find too that inducing negative emotional states makes moral judgments slightly more severe.

However, some have recently argued that the effect of incidental disgust on moral judgments is slight, inconsistent, and prone to replication failure (e.g. Mallon \& Nichols 2010; May 2014a; Huebner 2015). A recent meta-analysis of manipulation studies employing disgust confirms this interpretation (Landy and Goodwin 2015). These criticisms suggest that ordinary people are not as prone to simple emotional manipulation as researchers initially suggested. If someone makes you feel disgust by exposing you to a foul odor, you are not likely to judge that some entirely unrelated activity is morally more objectionable than you otherwise would have thought. This should be reassuring. Whether reasoning or emotion underlies moral judgment, the evidence does not support the cynical view that ordinary moral thought is suffused with irrationality (May 2018).

Thus far, incidental emotions do not seem to exert a significant influence on moral judgment. However, there is better evidence that integral emotions are central to moral thought, where "integral" emotions are those that are elicited by the object of moral evaluation itself, rather than by incidental conditions like foul odors. We will focus on disgust, since this has been the subject of manipulation studies reviewed above and since many philosophers are skeptical about disgust's value in moral thought (see, e.g., Nussbaum 2004; Kelly 2011).

One category that reliably elicits disgust involves so-called "purity" violations. For example, conservatives are especially likely to experience disgust in response to what they regard as sexually deviant behavior (Inbar et al. 2009). But liberals also regard some issues as matters of purity. Moral vegetarians are likely to experience disgust at the sight and smell of meat (Rozin et al. 1997). In these cases, however, one might wonder whether disgust remains incidental (Inbar and Pizarro 2014). It's possible that the object of evaluation merely happens to be disgusting. Perhaps the properties that make killing and eating sentient creatures morally wrong are distinct from the properties that make it disgusting.

However, another body of evidence suggests that people respond with disgust to moral violations that are not otherwise disgusting (see Chapman and Anderson 2013 for review). Participants are asked to recall a recent disgusting event and also to report which emotions they feel toward various moral violations. In the bulk of these studies, participants associate disgust 
not with bodily fluids or revolting food, primarily, but with moral violations, such as lying or taking advantage of an innocent person. The moral violations are generally instances of cheating, dishonesty, and exploitation (Kumar 2017a).

This evidence suggests that integral emotions, elicited by those properties of the object of evaluation that explain its wrongness, may play a role in moral judgment. You are disgusted by the hypocrisy of a politician and this is why you judge him negatively. However, while the evidence that moral violations elicit disgust is robust, the evidence that disgust produces moral judgment is not decisive. One reason is that the foregoing interpretation turns on a philosophical rather than scientific question about the nature of moral judgment. Are emotions concomitants of moral judgment? Or are they constitutive of moral judgment? Philosophers have recently argued that moral judgments consist in an emotional state, either wholly (Prinz 2007) or in part (Kumar 2016b). Empirical evaluation of sentimentalism turns in part on evaluating these philosophical theories about the nature of moral judgment.

It's commonly believed that sentimentalism enjoys a great deal of empirical support from recent empirical research. However, while there is suggestive indirect evidence for sentimentalism, direct evidence is much harder to find and turns on other, controversial positions in ethical theory. Still, the balance of evidence suggests that reasoning and emotions are implicated in moral judgment. Philosophers who wish to square their theories of moral thought with empirical evidence should therefore avoid extreme versions of rationalism or sentimentalism (see, e.g., Nichols 2004; Craigie 2011; Huebner 2015; Kumar 2016b). The result might resemble theories from the ancients, such as the Confucian philosopher Mencius (Morrow 2009). However, we retain the need to carry out the important project of discerning the relative roles played by emotion and reasoning in the development and deployment of moral cognition. Central to this project is understanding how reasoning and emotion interact in moral judgment.

\section{Interaction}

We've seen that reasoning, whether implicit or explicit, can directly affect moral cognition apparently without being mediated by emotion. We've also encountered some evidence for the reverse: that emotion can affect moral judgment independent of reasoning. We'll now examine evidence that reasoning and emotion can interact to generate moral judgment.

\subsection{Emotion affects Reasoning}

Some of the best evidence that emotions affect reasoning, even outside the domain of ethics, is the unfortunate phenomenon of motivated reasoning. Wishful thinking is a familiar example. A devoted fan of a sports team with a long track record of losses reasons that the team will win this game, because he wants it so badly to be true. A lover reasons that her partner hasn't cheated on her, despite the compelling evidence demonstrating otherwise, because she can't bear to accept the truth. A long-term cigarette smoker discounts the evidence that smoking tobacco causes cancer, because she'd otherwise have to give up her beloved habit.

Of course, sometimes reasoning is guided by a rather noble goal: to be accurate. One's reasoning is typically improved by triggering such motives, affecting the cognitive effort one puts into the reasoning, selecting optimal strategies for its success, and reducing cognitive biases. Overwhelming evidence, though, indicates that humans are often prone to having their reasoning 
guided by a variety of desires, motives, and goals (Kunda 1990), and sometimes emotions either constitute such motives or are intimately bound up with them.

While many experiments in the motivated reasoning literature do not specifically concern moral reasoning, some do. We already saw (in \$2.2) that studies on moral hypocrisy suggest that when we take the self-interested - rather than fair-option, we often rationalize the behavior as somehow justifiable (e.g. Batson et al. 1999). This suggests that egoistic motives can guide one's moral reasoning so that the self-serving behavior doesn't seem so morally problematic.

When engaged in motivated reasoning, we don't necessarily believe whatever we want to believe. Rather, passions guide our reasoning in subtle ways toward the desired conclusion. Kunda writes that the evidence suggests that "people motivated to arrive at a particular conclusion attempt to be rational and to construct a justification of their desired conclusion that would persuade a dispassionate observer" (1990: 482-3). So, when one's reasoning is affected by a goal, this appears to be tempered by independent reasoning that isn't motivated by that goal.

Moreover, emotions often seem to guide reasoning in less problematic ways. We already saw this (in §3.1) when discussing damage to the VMPFC in adulthood. When these patients develop so-called "acquired sociopathy," their gut reactions to the pros and cons of possible choices are impaired, especially regarding choices with social or moral import. Because they lack the appropriate "somatic markers," their decision-making suffers, often leading to irrational, even immoral, decisions (Damasio 1994). As we saw, it's unclear whether such decision-making deficits are driven by impaired moral judgment (Roskies 2003). But many theorists draw on studies of those with VMPFC damage to argue for the general importance of emotions to prospective reasoning in domains that have little to do with morality.

So emotion seems to affect reasoning in both positive and negative ways. Damasio's work on somatic markers suggests that emotions aid reasoning, while some kinds of motivated reasoning suggest that emotions corrupt reasoning. At the very least, emotions seem to affect one's moral reasoning by directing one's attention toward or away from certain forms of evidence. Future work may clarify the ways in which emotion negatively influences moral reasoning and the ways in which it positively influences it.

\subsection{Reasoning affects Emotion}

While emotions can guide, and even corrupt, one's reasoning, sometimes the tables are turned: reasoning can directly alter emotional responses. In fact, we already saw evidence of this (in $\S 2.1)$ with experiments suggesting that we can consciously overcome implicit biases or automatic responses to moral dilemmas, both of which arguably have affective components.

In addition, conscious reasoning can sometimes generate automatic responses (Saltzstein \& Kasachkoff 2004; Craigie 2011). Disgust or outrage, for example, might be a consequence of reasoning to the conclusion that Colonel Mustard wrongfully killed innocent Professor Plum with an axe in the conservatory. Or consider learning a new skill, such as driving a car (Kennett \& Fine 2009: 85), which takes conscious deliberate effort but is eventually automated and habitual. Though reasoning is a cognitive skill, not a motor ability, it is no different in this respect. It took effort to learn how to add and subtract numbers, but now you can do it without effort. Moral reasoning follows this same pattern. One can automatically judge to be immoral an instance of stealing, embezzlement, sexual assault, or incest, but some prior reasoning, whether conscious or unconscious, could have generated the judgment which is simply now being automatically deployed by searching in one's bank of moral norms (compare Nichols 2004). 
Moreover, we deliberately monitor our automatic responses and attempt to adjust them to best meet our needs. This might be fruitfully analyzed as a kind of education or attunement (Railton 2014; Sauer 2017).

Of course, these automatic moral responses might not always be emotional, but studies on moralization suggest that reasoning can directly affect emotions in particular. Consider vegetarians who eliminate meat from their diets for primarily moral reasons, not because they believe a meatless diet is healthier. Empirical evidence suggests that these "moral vegetarians" become disgusted by eating meat (Rozin et al. 1997), and not because they are antecedently prone to feeling disgust (Fessler et al. 2003). Rather, it seems their visceral responses changed in light of their reasoned moral belief. Similarly, after decades of unearthing the power of the tobacco industry and the detrimental health effects of smoking, people in the United States and elsewhere now moralize this habit and business enterprise. They not only judge smoking unhealthy but condemn those who smoke or sell tobacco as morally dubious. Accordingly, Americans are now more disgusted by the habit than they were decades ago and moral condemnation of smoking is more highly correlated with disgust toward it than the belief that the practice is unhealthy (Rozin \& Singh 1999). Again we have a case in which it seems that reasoning generated a moral belief that in turn changed a range of emotional responses. Of course, belief in the depravity of smoking or selling tobacco may owe some of its character or extent to emotions, such as anger toward those in the tobacco industry who tried to hide the link between smoking and cancer for financial reasons. But the change couldn't have been due to disgust alone, since that emotional response became prominent only after moral condemnation arose from the spread of this information.

\subsection{The Interplay of Reasoning and Emotion}

We suspect that one of the most interesting and fruitful areas of future research on moral judgment will concern the interaction between reasoning and emotion in moral judgment. As we've seen, there is evidence that reasoning influences moral judgment, even if much of this reasoning is unconscious. There is also evidence that emotion influences moral judgment, even if much of this evidence is indirect. More recently, we've examined how reasoning affects emotion and vice versa. We suspect that there is also a rich interplay between reasoning and emotion. On this topic, a long history of philosophical reflection on moral thought has the potential to guide scientific research.

Consider the method of reflective equilibrium, famously popularized in ethics and political philosophy by John Rawls (1971) and others. Often, we find ourselves with a conflict between a moral principle and intuitions about concrete cases. For example, you may explicitly endorse a principle that permits free economic exchange between rational agents without exception. However, even when no coercion is present, you also feel outraged at those who would try to purchase slaves who "voluntarily" sell themselves or to charge inflated prices for food in communities recently devastated by a natural disaster. You come to realize that your principle permits various activities (voluntary slavery, price gouging) that are, intuitively, morally wrong. So, it seems, you must either abandon the principle as it stands or override your intuitions about the cases.

Philosophers engage in reflective equilibrium, but so do ordinary people, even if less frequently. We all grapple with resolving conflicts between our more general moral principles and our judgments about specific cases. One study shows that people will revise their belief in a 
general moral principle, or at least their credence in it, after considering a concrete counterexample (Horne et al. 2015). And this change was not temporary, but persisted for hours. The philosophical tool, it seems, has its roots in ordinary moral thinking.

What sorts of psychological process lead to greater reflective equilibrium? When intuition is guided by emotion, it seems that reasoning and emotion play off one another, in a way that's fitting for our dual process minds (Campbell and Kumar 2012). One feels emotionally that an activity is wrong. One consciously realizes that a moral principle one embraced in full generality permits that activity. One then feels a pressure for consistency, and several routes to restoring consistency are possible. First of all, one may use reasoning to suppress one's feelings. Or, if moral feelings are particularly strong, they may lead one to abandon the principle. Yet another possibility is that one's convictions and feelings are equally strong, and the pain of inconsistency leads one to conscious reasoning about how to revise or amend the principle in a way that renders it compatible with one's feelings.

Two examples illustrate the interplay between reasoning and emotion in reflective equilibrium. Many people have a powerful emotional aversion to incest. However, an increasing number of people also have liberal attitudes toward sex. They believe that sexual intercourse between two consenting adults is always morally permissible (with an exception perhaps covering cases of sexual exploitation where there is a large imbalance of power). In our experience teaching Haidt's famous incest case, many students react initially with disgust and judge that it is morally wrong for two siblings to have consensual sex. However, after reflecting on their own liberal principles, some students, wisely or unwisely, eventually suppress their emotional response and suggest that incest in this case is (or at least might be) morally permissible. A similar reaction has been experimentally demonstrated in participants who read an evolutionary explanation of the aversion to incest that is meant to undermine the relevant intuitive moral judgment (Paxton et al. 2011).

Sometimes, by contrast, emotions win the battle in our efforts to achieve reflective equilibrium. The recent revolution in attitudes toward homosexuality may be driven in part by empathy (Kumar ms). As many more gay people began living open and candid lives, straight people increasingly discovered that a friend or family member or colleague is gay. Since they were more able to empathize with these people, they were more likely to appreciate the harms they experienced. This has led a tide of people in America and similar countries to accept homosexuality and abandon principles inconsistent with this new attitude-e.g., principles that prohibit "unnatural" sexual behavior.

Richmond Campbell and Victor Kumar (2012) have mapped out the interplay between reasoning and emotion in a form of moral reasoning that is not captured by the traditional model of reflective equilibrium, what they call "consistency reasoning." In consistency reasoning, you discover a conflict not between a principle and a concrete case intuition, but between intuitions. You discover, in short, that you are not treating like cases alike. For example, most people are likely to judge that cruelty toward a domestic animal is wrong. However, many of these people eat meat products from factory farms, which inflict a similar level of cruelty on livestock. What could make the difference? Why is one activity wrong and the other permissible? It strikes many people that one must either revise one's negative feelings about animal cruelty or revise one's feelings about factory-farmed meat.

Such consistency reasoning isn't fit only for academics (Kumar and Campbell 2016; Campbell 2017). The inconsistencies one recognizes needn't involve abstract principles familiar only to philosophers. Moreover, there is empirical evidence that people engage in consistency 
reasoning about familiar trolley cases (Petrinovich and O'Neill 1996; Schwitzgebel and Cushman 2012). If it's wrong to push a large man off a footbridge, then why is it permissible to sacrifice the one for the five by flipping a switch? Campbell and Kumar argue that reasoning and emotion are engaged in a potentially recursive interplay in consistency reasoning. People have emotional reactions to particular cases. They consciously reason that there is an inconsistency. Sometimes they identify a morally irrelevant difference. But then this difference can be fed back into our intuitions.

To see how this process plays out, consider Peter Singer's (1972) famous example of consistency reasoning (see Campbell and Kumar 2012: 292-5 for further detail). Suppose you are walking by a shallow pond and you see a young child drowning. Intuitively, you feel anticipatory guilt at the prospect of doing nothing, even if saving the child required ruining your new suit. Singer, however, asks us to consider the plight of starving children in the third world. Many people feel that donating money goes above and beyond the call of duty, and that abstaining is not an occasion for guilt. But Singer argues that there is no morally relevant difference between the two cases. In both, one can save a life at a slight personal cost. If you are obligated to save drowning children, it seems you are also obligated to save starving children in the third world. Some critics suggest that there is a morally relevant difference here. You are the only one who can save the drowning child, while many other people are in a position to save starving children. Singer counters: imagine that there are several other people standing around the pond doing nothing. Singer predicts correctly that you would still feel guilt at the prospect of not helping. What this illustrates is the recursive nature of the interplay between reasoning and emotion: reasoning about morally relevant differences, initially prompted by emotional conflict, can feed back into emotional evaluation.

Philosophical argumentation is often an attempt to regiment ordinary capacities for moral reasoning. It is therefore a source for better understanding the interplay between reasoning and emotion among ordinary moral agents. Moral philosophy can guide research into how reasoning and emotion combine to engender moral rationality.

\section{Conclusion}

We draw two main conclusions. First, on a fair and plausible characterization of reasoning and emotion, they are both integral to moral judgment. In particular, when our moral beliefs undergo changes over long periods of time, there is ample space for both reasoning and emotion to play an iterative role. Second, it's difficult to cleave reasoning from emotional processing. When the two affect moral judgment, especially across time, their interplay can make it artificial or fruitless to impose a division, even if a distinction can still be drawn between inference and valence in information processing.

To some degree, our conclusions militate against extreme characterizations of the rationalism-sentimentalism divide. However, the debate is best construed as a question about which psychological process is more fundamental or essential to distinctively moral cognition. The answer still affects both theoretical and practical problems, such as how to make artificial intelligence capable of moral judgment. At the moment, the more nuanced dispute is difficult to adjudicate, but it may be addressed by further research and theorizing.

Our conclusions also suggest limitations on some traditional threats to moral knowledge. Some skeptics, for example, contend that we can't possibly know right from wrong because moral judgment is a mere matter of non-cognitive feelings. Other skeptics attempt to debunk 
commonsense ethical intuitions, which are allegedly based on brute emotional responses. Such skeptical arguments are in danger of oversimplifying the nature of moral cognition. The processes that generate one's moral beliefs are often automatic and difficult to identify or articulate, but this does not imply that they are unsophisticated. So we may have cause to be more optimistic about the possibility of moral knowledge, even among people who don't regularly reflect on moral dilemmas.

Nevertheless, as we've highlighted, a mental process can involve reasoning or affective information processing without being reasonable or rational. Moral cognition is subject to the same sorts of biases that affect cognition generally. Our conclusions suggest that the way to attain and maintain moral knowledge will require improving both reasoning and emotion. Indiscriminately making people more compassionate or disgust-sensitive, independent of reasoning, would be disastrous. Similarly, improving reasoning without regard to emotional response may lead to clever rationalizations of immorality. Ethical architects aiming to nudge people toward better moral thinking would be wise to consider the interplay between reason and emotion.

\section{References}

Aharoni, E., Sinnott-Armstrong, W., \& Kiehl, K. A. (2012). Can psychopathic offenders discern moral wrongs? A new look at the moral/conventional distinction. Journal of Abnormal Psychology, 121(2), 484-497.

Batson, C. D., Thompson, E. R., Seuferling, G., Whitney, H., \& Strongman, J. A. (1999). Moral hypocrisy: appearing moral to oneself without being so. Journal of Personality and Social Psychology, 77(3), 525-537.

Blair, R. J. R. (1995). A cognitive developmental approach to morality: investigating the psychopath. Cognition, 57, 1-29.

Blair, R. J. R. (1997). Moral Reasoning and the Child with Psychopathic Tendencies. Personality and Individual Differences, 22: 731-9.

Blair, R. J. R., Jones, L., Clark, F., \& Smith, M. 1995. Is the Psychopath 'Morally Insane'? Personality and Individual Differences, 19 (5): 741-52.

Campbell, R. (2017). Learning from Moral Inconsistency. Cognition 167, 46-57.

Campbell, R., \& Kumar, V. (2012). Moral Reasoning on the Ground. Ethics, 122(2), 273-312.

Chapman, H. A., \& Anderson, A. K. (2013). Things Rank and Gross in Nature. Psychological Bulletin, 139(2), 300-327.

Craigie, J. (2011). Thinking and feeling: Moral deliberation in a dual-process framework. Philosophical Psychology, 24(1), 53-71.

Crockett, M. J. (2013). Models of morality. Trends in Cognitive Sciences, 17(8), 363-366.

Cushman, F. A., Young, L. L., \& Hauser, M. D. (2006). The Role of Conscious Reasoning and Intuition in Moral Judgment: Testing Three Principles of Harm, Psychological Science, 17(12), 1082-1089.

Damasio, A. R. (1994). Descartes' Error: Emotion, Reason, and the Human Brain. New York: Avon Books.

Dwyer, S. (2009). Moral Dumbfounding and the Linguistic Analogy. Mind \& Language, 24(3), 274-296.

Feltz, A. \& May, J. (2017). The Means/Side-Effect Distinction in Moral Cognition: A MetaAnalysis. Cognition 166: 314-327. 
Fessler, D. M. T., Arguello, A. P., Mekdara, J. M., \& Macias, R. (2003). Disgust sensitivity and meat consumption: a test of an emotivist account of moral vegetarianism. Appetite, 41(1), 31-41.

Gray, K., Young, L., \& Waytz, A. (2012). Mind perception is the essence of morality. Psychological Inquiry, 23(2), 101-124.

Greene, J. D. (2008). The Secret Joke of Kant's Soul. In W. Sinnott-Armstrong (Ed.), Moral Psychology, Vol. 3. MIT Press.

Greene, J. D. (2014). Beyond Point-and-Shoot Morality. Ethics, 124(4), 695-726.

Haidt, J. (2001). The Emotional Dog and Its Rational Tail. Psychological Review, 108(4), 814 834.

Haidt, J., Koller, S. H., \& Dias, M. G. (1993). Affect, Culture, and Morality, or Is It Wrong to Eat Your Dog. Journal of Personality and Social Psychology, 65(4), 613-628.

Hauser, M. D., Cushman, F. A., Young, L. L., Kang-Xing Jin, R., \& Mikhail, J. (2007). A Dissociation Between Moral Judgments and Justifications. Mind \& Language, 22(1), 121.

Helzer, E. G., \& Pizarro, D. A. (2011). Dirty liberals! Reminders of physical cleanliness influence moral and political attitudes. Psychological science, 22(4), 517-522.

Horgan, T., \& Timmons, M. (2007). Morphological Rationalism and the Psychology of Moral Judgment. Ethical Theory and Moral Practice 10(3), 279-295.

Horne, Z., Powell, D., \& Hummel, J. (2015). A Single Counterexample Leads to Moral Belief Revision. Cognitive Science, 39(8), 1950-1964.

Huebner, B. (2015). Do Emotions Play a Constitutive Role in Moral Cognition? Topoi, 34(2), 427-440.

Inbar, Y., \& Pizarro, D. A. (2014). Pollution and Purity in Moral and Political Judgment. In J. C. Wright \& H. Sarkissian (Eds.), Advances in Experimental Moral Psychology. Bloomsbury.

Inbar, Y., Pizarro, D. A., \& Bloom, P. (2009). Conservatives are more easily disgusted than liberals, Cognition and Emotion, 23(4), 714-725.

Kahane, G., Everett, J. A. C., Earp, B. D., Farias, M., \& Savulescu, J. (2015). "Utilitarian" judgments in sacrificial moral dilemmas do not reflect impartial concern for the greater good. Cognition, 134(C), 193-209.

Kahane, G., Wiech, K., Shackel, N., Farias, M., Savulescu, J., \& Tracey, I. (2012). The neural basis of intuitive and counterintuitive moral judgment. Social Cognitive and Affective Neuroscience, 7(4), 393-402.

Kahneman, D. (2011). Thinking, Fast and Slow. New York: Farrar, Straus, and Giroux.

Kauppinen, A. (2013). A Humean theory of moral intuition. Canadian Journal of Philosophy, 43(3), 360-381.

Kelly, D. R. (2011). Yuck! The Nature and Moral Significance of Disgust. Cambridge, MA: MIT Press.

Kennett, J., \& Fine, C. (2009). Will the Real Moral Judgment Please Stand Up? Ethical Theory and Moral Practice, 12(1), 77-96.

Kohlberg, L. (1973). The Claim to Moral Adequacy of a Highest Stage of Moral Judgment. Journal of Philosophy, 70(18), 630-646.

Kumar, V. (2016a). Psychopathy and Internalism. Canadian Journal of Philosophy, 46: 318-45.

Kumar, V. (2016b). The Empirical Identity of Moral Judgement. Philosophical Quarterly 66(265): 783-804. 
Kumar, V. (2017a). Foul Behavior. Philosophers' Imprint 17: 1-17.

Kumar, V. (2017b). Moral Vindications. Cognition 167, 124-134.

Kumar, V. (ms). The Weight of Empathy.

Kumar, V. \& Campbell. (2016). Honor and Moral Revolution. Ethical Theory and Moral Practice, 19: 147-59.

Kumar, V. \& Campbell, R. (ms). Why We Are Moral: The Evolutionary Foundations of Moral Progress.

Kumar, V. \& May, J. (forthcoming). How to Debunk Moral Beliefs. J. Suikkanen \& A. Kauppinen (eds.), The New Methods of Ethics.

Kunda, Z. (1990). The Case for Motivated Reasoning. Psychological Bulletin, 108(3), 480-498.

Landy, J. F., \& Goodwin, G. P. (2015). Does Incidental Disgust Amplify Moral Judgment? A Meta-Analytic Review of Experimental Evidence, Perspectives on Psychological Science, 10(4), 518-536.

Mallon, R., \& Nichols, S. (2010). Rules. In J. Doris et al. (eds.), The Moral Psychology Handbook. Oxford University Press.

Mikhail, J. (2011). Elements of Moral Cognition. Cambridge: Cambridge University Press.

May, J. (2014a). Does Disgust Influence Moral Judgment? Australasian Journal of Philosophy, 92(1), 125-141.

May, J. (2014b). Moral Judgment and Deontology, Philosophy Compass 9(11), 745-755.

May, J. (2018). Regard for Reason in the Moral Mind. Oxford University Press.

Morrow, D. (2009). Moral psychology and the "Mencian creature." Philosophical Psychology, 22(3), 281-304.

Nichols, S. (2004). Sentimental Rules. Oxford University Press.

Nussbaum, M. C. (2004). Hiding from Humanity. Princeton University Press.

Paxton, J. M., Ungar, L., \& Greene, J. D. (2011). Reflection and Reasoning in Moral Judgment. Cognitive Science, 36(1), 163-177.

Petrinovich, L., \& O'Neill, P. (1996). Influence of wording and framing effects on moral intuitions. Ethology and Sociobiology, 17(3), 145-171.

Prinz, J. J. (2007). The Emotional Construction of Morals. Oxford University Press.

Railton, P. (2014). The Affective Dog and Its Rational Tale: Intuition and Attunement. Ethics, 124(4), 813-859.

Rawls, J. (1971). A Theory of Justice. Harvard University Press.

Roskies, A. L. (2003). Are Ethical Judgments Intrinsically Motivational? Lessons From "Acquired Sociopathy." Philosophical Psychology, 16(1), 51-66.

Royzman, E. B., Kim, K., \& Leeman, R. F. (2015). The curious tale of Julie and Mark: Unraveling the moral dumbfounding effect. Judgment and Decision Making, 10(4), 296313.

Royzman, E. B., Leeman, R. F., \& Baron, J. (2009). Unsentimental ethics: Towards a contentspecific account of the moral-conventional distinction. Cognition, 112(1), 159-174.

Rozin, P., Markwith, M., \& Stoess, C. (1997). Moralization and becoming a vegetarian: The transformation of preferences into values and the recruitment of disgust, Psychological Science, 8(2), 67-73.

Rozin, P., \& Singh, L. (1999). The Moralization of Cigarette Smoking in the United States. Journal of Consumer Psychology, 8(3), 321-337.

Saltzstein, H. D., \& Kasachkoff, T. (2004). Haidt's Moral Intuitionist Theory: A Psychological and Philosophical Critique. Review of General Psychology, 8(4), 273-282. 
Sauer, H. (2017). Moral Judgments as Educated Intuitions. MIT Press.

Saver, J. L., \& Damasio, A. R. (1991). Preserved access and processing of social knowledge in a patient with acquired sociopathy due to ventromedial frontal damage. Neuropsychologia, 29(12), 1241-1249.

Schnall, S., Haidt, J., Clore, G. L., \& Jordan, A. H. (2008). Disgust as Embodied Moral Judgment. Personality and Social Psychology Bulletin, 34(8), 1096-1109.

Schwitzgebel, E., \& Cushman, F. A. (2012). Expertise in Moral Reasoning? Mind \& Language, $27(2), 135-153$.

Seidel, A., \& Prinz, J. J. (2013a). Mad and glad: Musically induced emotions have divergent impact on morals. Motivation and Emotion, 37(3), 629-637.

Seidel, A., \& Prinz, J. J. (2013b). Sound morality: Irritating and icky noises amplify judgments in divergent moral domains. Cognition, 127(1), 1-5.

Singer, Peter (1972). Famine, Affluence, \& Morality. Philosophy \& Public Affairs, 1(3), 229243.

Stewart, B. D., \& Payne, B. K. (2008). Bringing automatic stereotyping under control: implementation intentions as efficient means of thought control. Personality and Social Psychology Bulletin, 34(10), 1332-1345.

Taber-Thomas, B. C., Asp, E. W., Koenigs, M., Sutterer, M., Anderson, S. W., \& Tranel, D. (2014). Arrested development: early prefrontal lesions impair the maturation of moral judgement. Brain, 137(4), 1254-1261.

Wheatley, T., \& Haidt, J. (2005). Hypnotic Disgust Makes Moral Judgments More Severe. Psychological Science, 16(10), 780-784.

Yoder, K. J., \& Decety, J. (2014). Spatiotemporal neural dynamics of moral judgment: A highdensity ERP study. Neuropsychologia, 60, 39-45.

Young, L. L., Camprodon, J. A., Hauser, M. D., Pascual-Leone, A., \& Saxe, R. (2010). Disruption of the right temporoparietal junction with transcranial magnetic stimulation reduces the role of beliefs in moral judgments. Proceedings of the National Academy of Sciences, 107(15), 6753-6758.

Young, L. L., Cushman, F. A., Hauser, M. D., \& Saxe, R. (2007). The Neural Basis of the Interaction between Theory of Mind and Moral Judgment. Proceedings of the National Academy of Sciences, 104(20), 8235-8240.

\section{Further Readings}

Glenn, A. L., \& Raine, A. (2014). Psychopathy. New York University Press.

Greene, J. (2013). Moral Tribes: Emotion, Reason, and the Gap Between Us and Them. Penguin.

Helion, C., \& Pizarro, D. A. (2014). "Beyond Dual-Processes: The Interplay of Reason and Emotion in Moral Judgment." In Handbook of Neuroethics, ed. by J. Clausen \& N. Levy. Dordrecht: Springer Netherlands.

Liao, S. M. (ed.) (2016). Moral Brains: The Neuroscience of Morality. Oxford University Press.

Maibom, H. L. (2010). "What Experimental Evidence Shows Us about the Role of Emotions in Moral Judgement." Philosophy Compass, 5(11), 999-1012.

Moll, J., Zahn, R., de Oliveira-Souza, R., Krueger, F., \& Grafman, J. (2005). "The Neural Basis of Human Moral Cognition." Nature Reviews Neuroscience 6(10), 799-809. 
Nado, J., Kelly, D. \& Stich, S. (2009). “Moral Judgment.” In J. Symons \& P. Calvo (eds.), The Routledge Companion to Philosophy of Psychology. Routledge.

Pizarro, D. A. (2000). "Nothing More than Feelings?" Journal for the Theory of Social Behaviour 30(4), 355-375. 